\title{
A "EMBOLADA" EM MACUNAÍMA
}

\section{Raimunda B. Batista}

\section{Professora do Departamento de Ciências Sociais da Universidade Estadual de Londrina}

Os intelectuais do modernismo brasileiro tiveram como preocupação a redefinição da cultura brasileira tomando como ponto de partida a cultura popular e o folclore brasileiros. Em Macunaíma, Mário de Andrade aproveita os mais variados elementos da cultura popular, dando-lhes uma configuração erudita. Entre esses elementos destacamos o aproveitamento da embolada que, enquanto modo de cantar, possui uma forte estrutura poética, podendo ser aproveitada na prosa de ficção, conservando o seu ritmo e forma.

Palavras-chave: Cultura brasileira, cultura popular, literatura, literatura oral, modernismo brasileiro.

\section{Introdução}

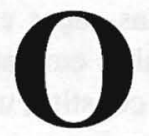

$\mathrm{s}$ intelectuais do Modernismo, na sua perspectiva revolucionária de mudança nos diversos setores do conhecimento, tinham como meta prioritária o combate à cultura importada, "branca", que desconhecia ou não apresentava com realce, a especificidade dos valores "mestiços"e imitava o modelo europeu.

Como bem demonstra Antonio Candido, a arte primitiva, o folclore e a etnografia, desempenharam um papel importante na definição ideológica das estéticas modernas, quando retomam, reelaboram e fazem ressurgir os elementos ditos arcaicos e populares oprimidos pelo academicismo elitista.Na verdade, só um tratamento mais autêntico que respeite a riqueza e o modo de ser da manifestação desses elementos populares, produzirá um conhecimento que retrate com fidelidade a simplicidade, a beleza e o dia-a-dia, da capacidade criadora do povo.

O movimento modernista, redefinindo a cultura brasileira a partir da cultura popular, pretendeu construir uma atitude crítica que, mesmo sofrendo limitações em consequência da realidade sócio-cultural da época, abriu caminhos para outras realidades que surgiram e que, certamente, surgirão. No entanto, torna-se também ele distante das manifestações populares. É sempre um movimento de eruditos. Com efeito, mesmo sendo uma tentativa de capturar a realidade cultural brasileira, não conseguiu ultrapassar os seus próprios limites e chegar até à população que, continua a preferir a literatura de feira dos cantadores repentistas, já que esses retratam as mais modernas concepções de vida e do mundo e respeitam a oralidade dessa população.

Macunaíma, obra que transgride os cânones literários, realiza essa passagem do oral ao escrito e nela Mário de Andrade procura dinamizar o folclore e a cultura popular, mas elabora uma rapsódia erudita, conseqüentemente voltada ao gosto erudito, embora consiga apresentar um gênero cultural que é "expressão de nacionalidade", dentro de uma cultura que sofre a pressão de núcleos colonizadores que lhes dão um cunho insignificante e sempre que tentam reinterpretá-la lhes imprime um caráter alienante.

Seria interessante que o povo assumisse sua própria literatura, os seus valores culturais, sem que os intelectuais ficassem lhe mostrando os caminhos a serem seguidos, dirigindo-o e substituindo-o nas suas formas concretas de expressão cultural.Sempre é necessário um movimento que parta do mundo erudito para explicar às camadas não eruditas aquilo que ela quer manifestar e "não sabe". Isso porque o erudito, $o$ artístico estão permeados por valores das culturas dominantes, que tentam dirigir, organizar aquelas manifestações que não conseguem compreender. 
Mário de Andrade está entre os autores que viam a cultura popular como um elemento nacional autêntico e, partindo do conhecimento dessa concepção de cultura, tentou conduzir sua produção literária dentro de um projeto estético-ideológico, com o aproveitamento das fontes populares, em busca de uma literatura e cultura brasileiras que pudessem assumir uma conotação crítica dessas mesmas fontes.

\section{Conceituação de embolada}

Para Raul Cortázar, o folclore significa "todas as manifestações tradicionais com valor funcional na vida do povo. O folclore (...) aparece como projeção, como ambiente, tema, caráter, elemento ou episódio incorporado à obra particular de um autor culto e perfeitamente determinado..."1. Para especificá-lo é necessário ligá-lo ao adjetivo correspondente: folclore musical, poético, religioso, etc.

A embolada, processo da poesia popular incorporada por Mário de Andrade a Macunaíma, pode se enquadrar no chamado "folclore poético-musical", visto que possui características específicas desse gênero: ritmo ligeiro e rimas repetidas, improvisação e refrão, texto cômico, satírico ou descritivo com aliterações e onamatopéias, enumeração, associação de imagens e de idéias feitas, histórias ou crítica de fatos ocorridos.

Em sua obra Mário de Andrade:ramais e caminho, Telê Porto Ancona Lopez analisa o significado da embolada para Mário, tomando como referencial os contatos deste com os cantadores nordestinos e com obras de estudiosos do processo, que o levaram a compreender o "espírito do gênero" : o uso da linguagem e a ressaltar a importância da palavra na descrição, na enumeração e mesmo na divagação, tendo como tema a exaltação individual ou ufanista.

Paralela a essa conceituação, temos aquela percebida por Mário em seu texto: "Notas sobre o cantador nordestino", onde conclui que os termos "embolar"e "embolada" são derivados de "bola"que significa "cabeça", "tino", "inteligência", completando "(...) derivou hoje um confusionismo de terminologia que vai dando aos poucos prá bola, embolar e embolada um valor técnico musical que não depende apenas da inteligência mas do processo de execução." Essa conceituação de Mário possui coerência à medida em que a embolada, envolvendo uma profusão de palavras deslizando umas sobre as outras, rápida e rítmicamente, guardando costumes e historiando ou criticando fatos ocorridos, exige dos repentistas rapidez e desembaraço verbal, um bom "tino"enfim, para executar o processo poético-musical a contento.

\section{Aproveitamento da embolada na obra}

A transposição do material folclórico ao plano erudito na obra andradiana, constitui uma tentativa de diminuir a

\footnotetext{
LATOUR, Olga Fernández Botas. Folklore y poesía argentina.

Buenos Aires, Guadalupe, 1969
}

distância existente entre a arte popular e a erudita e esse aproveitamento ocorre a partir de alguns aspectos estudados por Florestan Fernandes: 1. Aproveitamento dispersivo. $\mathrm{O}$ autor usa um ou outro elemento esparso em sua obra, não constituindo essa técnica das mais importante por ele utilizadas; 2. Interseção.É uma das formas mais utilizadas. Aparece sempre nas suas poesias, mas onde surge de forma mais perfeita é em Macunaíma; 3. Assimilação de técnicas e formas populares. Aqui Mário dá um relevo especial à linguagem, na sua tentativa de construir um "brasileiro escrito"; 4. Estilização. Aproveitamento livre de temas folclóricos, utilizados por Mário com perfeição, sendo um bom exemplo ainda Macunaíma.

A inserção da embolada na narrativa, pode ser enquadrada nos dois últimos aspectos apresentados. Mário assimilou formas e técnicas da poesia popular nordestina, utilizou modas, cocos e lundus e estilizou essas técnicas, não só em Macunaíma, como em outras obras, com a "desaristocratização" de temas, processos e formas euditas, por meio de formas e processos populares "...numa manifestação típica do 'caráter nacional' aspiração do escritor que tenta um 'abrasileiramento'da arte erudita através da arte popular".

O ritmo da embolada que ele usa na narrativa, acompanha o mesmo processo comum entre os "emboladores" nordestinos. As palvras "embolam" umas sobre as outras, em forma própria e ritmo ligeiro, trabalhadas pelo autor na economia do texto,com pouco uso de vírgulas, dinamizando o tema, com uma musicalidade própria dessa modalidade popular.

O refrão utilizado por Mário obedece a um único padrão e nos exemplos rastreados no texto aparecerão sempre sublinhados. Para exemplificar tomemos o processo utilizado no capítulo 10, p.114: “A gente enxergava os conhecidos, os pais-das-árvores os pais-das-aves os pais-das-caças e os parentes manos pais mães tias cunhadas cunhãs cunhatãs, tôdas essas estrêlas..." A variedade estrófica constitui uma reelaboração dos modelos populares para o erudito.

A quase total ausência de vírgulas nos trechos de embolada é própria da dinâmica do processo e é o que confere a essa modalidade popular que é "enrolado", "embrulhado", um ritmo interessante, atraente, gostoso de se ouvir.

Utilização da embolada na narrativa

Mário utilizou a embolada na sua narrativa, seguindo os seguintes passos:

- Macunaíma no seu mundo primitivo;

- Macunaíma e seu contato com o mundo tecnizado;

- Macunaíma e a busca do talismã perdido;

- Macunaíma e o retorno ao mundo primitivo.

A embolada transposta para a obra obedece a dois momentos que considero mais constantes e de maior importância: enquanto sátira e enquanto enumeração descritiva com associação de imagens. situações:

Enquanto sátira, a embolada aparece nas seguintes 
- Macunaíma no seu mundo primitivo

"Falou pros manos que inda tinha muita piaba muito jeju muito matrinchão e jatuaranas, todos êsses peixes do rio..."(cap.2,p.17). Quando a fome assola o mocambo, Macunaíma, apesar de tudo, resolve se divertir às custas dos irmãos, madando-os "bater timbó"numa evidente situação de ironia, dada a situação precária em que estavam, definindo assim uma outra característica sua: a mentira aliada à troça, esta também uma característa da embolada escarnecer das pessoas.

"Depois foram-se embora com prazer e alegria, bailando mais que bailando, seguidas de futebóleres águias pequenos xodós seresteiros, tôda essa rapaziada dorê"'. (cap.3.p.30). Por ocasião do nascimento do filho de Macunaíma com $\mathrm{Ci}$, a sátira aparece ligada à condição social das pessoas que visitaram o recém-nascido, acentuada pelo refrão: "Tôda essa rapaziada dorê." Nesse trecho há ainda uma inserção de um versinho de cantiga de pastoril: "com prazer e alegria."

- Macunaíma e seu contato com o mundo tecnizado

"De-manhãzinha ensinaram que tôdos aquêles piados berros cuquiadas sopros roncos esturros não eram nada disso não, eram mas cláxons campainhas apitos buzinas e tudo era máquina." (cap. 5, p. 51). Nos seus primeiros contatos com o mundo civilizado, Macunaíma demonstra seu espanto ao perceber que na civilização todas as coisas eram máquinas, o que o leva a sentir respeito por elas e a observar que, mesmo tendo sido criadas pelo homem, acabam por dominálo.

“(...) e já estava mais que assente que pelas leis de catalepse elipse síncope metonímia metafonia metátese próclise prótese aférese apócope haplologia etimologia popular tôdas essas leis, a palavra botoeira (...)" (cap.11, p.113). Sátira com conotação crítica à excessiva preocupação dos gramáticos e puristas com as figuras de sintaxe,regras e normas que distancia ainda mais a linguagem falada da escrita, mostrando o cômico do uso e abuso de fórmulas e explicações para o significado das palavras.

- Macunaíma e a busca do talismã perdido

"Então Macunaíma emprestou da patroa da pensão uns pares de bonitezas, a máquina ruge, a máquina meia de seda, a máquina combinação com cheiro de cascacasacaca, a máquina cinta aromada com capim cheiroso, a máquina decotelê úmida e patchuli, a máquina mitenes, tôdas essas bonitezas(...)" (cap.6, p.63). Após sua morte e ressurreição na casa de Venceslau Pietro Pietra, Macunaíma resolve mudar de tática para chegar até ele e reaver a muiraquitã. Decide ir visitá-lo transformado em francesa, sem utilizar a magia para esse fim e sim os acessórios de uso feminino, especificamente usado pelas mulheres para a conquista do homem. Sátira em torno dos objetos femininos que denomina "máquina", ressaltando a grande importância que lhes é dada no mundo civilizado, o que leva Macunaíma a adotá-los por sentir que dessa forma colocar-se-á em pe' de igualdade com o imigrante peruano que pertencia à "civilização".

"Tinha turquesas esmeraldas berilos seixos polidos, ferragem com forma de agulha, crisólita pingo d'água tinideira esmeril lapinha ovo-de-pomba osso-de-cavalo machados facões flechas de pedra lascada,grigris rochedos elefantes petrificados, colunas gregas, deuses egípcios, budas javaneses, obeliscos lesas mexicanas, ouro guianense, pedras ornitomorfas de Iguape, opalas do igarapê Alegre, rubis e granados do rio Gurupi, itamotingas do rio das Garças, (...) tinha tôdas essas pedras no grajaú."(cap.6, p.65). Ofendido por ter sido chamado regatão por Macunaíma, Venceslau Pietro Pietra mostra-lhe sua coleção de pedras de todos os tipos e procedências, misturadas e guardadas num único lugar, demonstrando comportamento típico de classe em ascensão, que se dedica a acumular coisas pelo prazer de acumular, sem atentar para o seu significado e importância.

"E tôdas essas pedras já tinham sido vespas formigas mosquitos carrapatos animais passarinhos gentes e cunhãs e cunhatãs e até as graças das cunhãs e das cunhatãs (...)" (cap.6, p.69). O herói satiriza a coleção do imigrante-regatão, sem contudo penetrar-lhe o signicado e, mostrando a inveja que sente do colecionador, decide-se, pela lei do menor esforço, a colecionar palavras-feias.

"Já tinha muita gente lá, gente direita, gente pobre, advogados garçons pedreiros meias-colheres deputados gatunos, tôdas essas gentes e a função ia principiando." (cap.7, p.73-4). "(...) distribuiu uma vela acesa pra cada um dos marinheiros, marcineiros jornalistas ricaços gamelas fêmeas empregados-públicos, muitos empregados-públicos! tôdas essas gente e apagou o bico de fás(...)" (cap.7, p.74)." Tôda a gente vendedores bibliófilos pés-rapados acadêmicos banqueiros, tôdas essas gentes dançando(...)" (cap.7, p.77). A enumeração dos freqüentadores de terreiros de macumba provenientes dos mais variados estratos, desde as camadas mais pobres, marginalizadas, até aos membros da elite econômica e política, numa espécie de convivência compulsória em obediência a um mesmo ritual religioso expressa a fragilidade e vulnerabilidade que atinge essas camadas. A sátira embolada trabalhada nesse capítulo segue um crescendo,onde a mistura e o nivelamento das classes sociais, deixa clara a intenção de desmistificá-las, ou antes, sugere que na prática, essas diferenças não existem. $\mathrm{O}$ denominador comum - a macumba - faz com que todos se encontrem num mesmo nível, uns para resolver os seus problemas existenciais, outros a sua própria sobrevivência.

"E pra acabar tôdos fizeram a festa juntos comendo um bom presunto e dançando um samba de arromba em que tôdas essas gentes se alegraram (...)" (cap.7, p.82). Neste trecho, Mário de Andrade inclui um verso de cantiga de roda ("tôdos fizeram a festa juntos"), nivelando ainda mais as pessoas presentes na macumba, marcando a oposição entre a comida (presunto) e a dança (samba), que agrada igualmente a todos.

- Macunaíma e o retorno ao mundo primitivo

Ächou os dois brincos achou os dedões achou as orelhas os nuquiiris o nariz, tôdos esses tesouros e prendeu todos nos lugares dêles com sapé e cola de peixe (...)" (cap.17, p.214). Trecho importante quanto ao grau de sátira, pois o 
herói de volta ao seu mundo primitivo, trazendo consigo elementos da civilização e perdendo-os na luta com a Uiara, após achá-los dá-lhes o mesmo tratamento que aos seus próprios membros arrancados, colando-os com "sapé e cola de peixe", colocando-os em um mesmo nível de importância, que se contrapõe ao da civilização de onde retornara.

No levantamento das emboladas enquanto enumeração descritiva com associação de imagens, utilizarei os mesmos ítens adotados na embolada enquanto sátira.

- Macunaíma no seu mundo primitivo

"Porém respeitava os velhos e frequentava com aplicação a murua a poracê o torê o bacorocô a cucuicogue, tôdas essas danças religiosas da tribo." (cap.1, p.9). Macunaíma, desde a infância mostrava tendências bem marcadas de preguiça e sensualidade. No entanto, suas contradições maiores surgem em dois momentos bastante decisivos: 1. de modo positivo, quando frequüentando os rituais e as danças religiosas da tribo, ele demonstra um respeito e uma necessidade de conviver com seu povo, se inteirar de seus valores, buscar suas raízes e penetrar naquilo que é comum a todos - a comunidade. 2. em um momento muito contraditório ele nega a participação comunitária. É a sua recusa ao trabalho tribal, dever de todos, que é o componente maior de perpetuação, reprodução e coesão do próprio grupo. É o Macunaíma individualista. Nega, com a preguiça, o compromisso para com os outros.

"E eram muitos mosquitos, piuns maruins arurus tatuquiras muriçocas meruanhas mariguis borrachudos varejas, toda essa mosquitada". (cap.2, p.18). Nesse trecho, além de enganar os irmãos, Macunaíma finge trabalhar, usando de esperteza, demonstrando fadiga para fugir às obrigações.

“... e carregou tejupar marombas flechas piquás sapiquás corotas urupemas redes, todos êsses trens pra um aberto..." (cap.2, p.19). O herói, num repente de solidariedade para com os parentes famintos, transporta os objetos da tribo enumerados, para uma região de fartura, mas logo em seguida leva-os de volta ao mocambo, numa nova atitude egoísta, quando vê que a mãe iria ajudar os irmãos. É o herói contraditório por natureza, transitando inconscientemente entre o "bem" e o "mal".

"Jiguê viu que a maloca estava cheia de alimentos, tinha pacova tinha milho tinha macacheira, tinha aluá e cachiri, tinha maparás e camorins pescados, maracujá-michira ata abio sapota sapotilha, tinha passoca de viado e carne fresca de cutiara, todos êsses comes e bebes bons..." (cap.2, p.23). Jiguê ao perceber que Macunaíma lhe tomara a companheira é advertido por Maanape - o feiticeiro - que o herói é agora homem feito, provavelmente associando o fato de agora estarem vivendo com fartura às artes mágicas do herói, que de piá passou a adulto.

"E os sabiás, o sabiàcia o sabiàpoca o sabiàuna o sabiàpiranga o sabiàgonga que quando come não me dá, o sabiá-barranco o sabiá-tropeiro o sabiá-laranjeira o sabiágute todos êsses ficaram pasmos..." (cap.5, p.49). Os "seres do mato" demonstram admiração diante dos três irmãos, um louro, um vermelho, outro negro agora simbolizando as três raças, ou seja, as três culturas nas suas diferenças: o branco, europeu - dominação, o vermelho, nativo - liberdade e o negro - escravo.

- Macunaíma e o mundo tecnizado

"... e a moeda tradicional não era mais cacau, em vez, chamava arame contos contecos milreis bvorós tostão duzentorreis quinhentorreis, cinquenta paus, noventa bagarotes, e pelegas cobres xenxéns caraminguás selos bicosde-coruja massuni bolada calcáreo gimbra siridó bicha e pataracos, assim,..." (cap.5, p.49). Na chaegada à civilização, o herói sente o primeiro impacto, ao ver a diferença existente entre a moeda usada na cidade "macota"e o cacau, constatando que a moeda do seu mundo não tinha nenhum valor na civilização. Percebe agora que o mundo possui uma divisão. Há diferenças, os valores mudam. E tudo ali se define em ter ou não ter moeda. $\mathrm{E}$ os encantos do conforto e do bem-estar o seduzem, embora isso deixe Macunaíma contrariado, porque mesmo assim precisaria em breve trabalhar para sobreviver. Os conflitos externos da sociedade agora são "internalizados"em Macunaíma, que pensa então em retornar aos seu mundo.

- Macunaíma e a busca do talismã perdido

“... que dá tôdas as frutas, cajus cajás cajàmangas mangas abacaxis jaboticabas graviolas sapotis pupunhas pitangas guajiru cheirando sovaco de preto, tôdas essas frutas e é mui alta." (cap.5, p.53). Sabendo que a muiraquitã perdida está em poder de um imigrante peruano, Macunaíma resolve ir até ele mesmo contrariando o irmão Maanape (feiticeiro), que desconfia que o regatão seja o gigante Piaimã, comedor de gente. Lá chegando o herói encontra a árvore mágica Dzalaúra-Iegue, que dá todas as frutas tropicais.

"... aparava os macucos macacos micos mutuns jacus jaós tucanos, tôdas essas caças.” (cap.5, p.53). Os irmãos resolvem caçar enquanto comem as frutas da árvore mágica, mas quando macunaíma está esperando a cça, Venceslau Pietro Pietra acorda e quer saber o que está contecendo. Confirmando a suspeita de Maanape, o migrante é mesmo o gigante Piaimã, comedor de gente.

"Saudaram todos os santos da pagelança, o Bôto Branco que dá os amôres Xangô, Omulu, Iroco Ochosse, a Boiúna Mãe feroz, Obatalá que dá fôrça pra brincar muito, todos êsses santos e o çairê se acabou." (cap.7, p.76). Essa enumeração dá bem uma idéia das entidades que freqüentam os terreiros das religiões de origem africana, numa união que redimensiona as manifestações religiosas em completo sincretismo.

"Porém não podia pescar nem de frecha nem com timbó nem cunambi nem tigui nem macerá nem no pari nem com linha nem arpão nem juqiaí nem sararaca nem gaponga nem de poita nem de cassuá nem itapuá nem de giqui nem de grozera nem de gererê guê tresmalho aparador gungá(...), todos êsses objetos armadilhas e venenos porque não possuía nada disso não." (cap.11, p.130). Nessa enumeração ligada a objetos de pesca, Macunaíma, após ter perdido a aposta com o Chuvisco, resolve pescar e fica muito contrariado 
por ver que não possui instrumento de pesca, então decide partir para o engodo e a magia. Trama enganar o Inglês a fim de lhe tomar o anzol e após tomá-lo, transforma-o na "máquina London Bank". O herói vê-se desprovido de obter sua subsistência e num confronto direto com o Inglês, apossa-se daquilo que lhe era necessário.

- Macunaíma e o retorno ao mundo primitivo

“... e era o bando de araras vermelhas e jandaias, todos êsses faladores, era o papagaio-trombeta era o papagaio-curraleiro era o periquito cutapado era o xarã o peito-roxo o ajuru-curau o ajuru-curica arari ararica araraúna araraí araguaí arara-taua maracanã maitaca arara-piranga castorra teriba camiranga anaca anapura canindés tuins periquitos todos êsses, o cortejo..." (cap.15, p.179). Vei, a sol num impulso de vingança, derrama um calorão intenso sobre os três irmãos que estão retornando ao Uraricoera. Macunaíma que é ainda imperador do Mato Virgem, lançando uma frase no ar é imediatamente protegido pelo seu "cortejo sarapintado". Essa enumeração é uma das mais bonitas da narrativa e revela o grau de importância do herói nas terras onde imperava.

"Não fazia mal que fôsse brilho inútil não, pelo menos era o mesmo de todos êsses parentes de todos os pais dos vivos da sua terra, mães pais manos cunhãs cunhadas cunhatãs, todos êsses conhecidos que vivem agora do brilho inútil das estrêlas." (cap.17, p.215). O herói percebendo que não havia mais sentido em viver nem no seu mundo primitivo ao qual não se integrava mais, nem no mundo civilizado onde não conseguiria sobreviver, decide ir para o céu, viver "o brilho inútil das estrêlas". Sentindo a inutilidade de sua vida, que não era mais do que "um se deixar viver", opta por uma transformação que o colocará distante do sofrimento, da tristeza, dos males, decidindo assim, por uma posição mais coerente na sua vida de incerências.

\section{CONCLUSÃO}

A embolada possuindo um estilo solto e livre para cada estrofe, liga-se às sequências das ações do personagem, seja para historiá-las, seja para explicitá-las, exaltando-as. Sua utilização foi bastante pertinente em relação à guarda de costumes da tribo, à enumeração dos seres do mundo primitivo, enfim a tudo o que compõe esse universo, constituindo também a própria visão do herói no seu confronto com o mundo civilizado.

O lado cômico, satírico e crítico é mostrado com clareza, revelando a percepção de Mário de Andrade ao notar que as palavras deslizando umas sobre as outras, aparentemente sem função, possuem grande força expressiva e musicalidade, funcionando como corte na narrativa, chegando mesmo a causar a impressão de que uma história foi interrompida para que se pudesse ouvir um desafio

Mesmo no aspecto cômico, a embolada se reveste de um componente crítico. Aí, Mário conseguiu captar as formas mais significativas, construindo uma obra de profundo lirismo, onde sente-se também a característica marcante da obra andradiana, no que concerne às manifestações da cultura popular.

\section{REFERÊNCIAS BIBLIOGRÁFICAS}

ALVARENGA,Oneyda - "Comentários e alguns cantos e danças no Brasil”. In: Revista do Arquivo Municipal, a.7, v.80. São Paulo, nov.dez.1941.

ANDRADE, Mário de - Macunaíma: o herói sem nenhum caráter. São Paulo, Martins, 1973.

BOSI, Alfredo - História concisa da literatura brasileira. São Paulo, Cultrix, 1970.

LATOUR, Olga Fernández Botas - Folklore y poesía argentina. Buenos Aires, Guadalupe, 1969.

BARROSO, Gustavo - Ao som da viola. Rio de Janeiro, Leite Ribeiro, 1921.

CÂNDIDO, Antonio - Literatura e sociedade.São Paulo, Nacional,1976.

CASCUDO, Luís da Câmara - Dicionário do folclore brasileiro. Rio de Janeiro, MEC-INL, 1954.

- Literatura oral no Brasil. Brasília, Rio de

Janeiro, INL-MEC, José Olympio, 1978.

CARVALHO, Rodrigues de - Cancioneiro do Norte. Paraíba, Tipografia São Paulo, 1928.

FERNANDES, Florestan - O folclore em questão. São Paulo, Hucitec, 1978.

LOPEZ, Telê Porto Ancona - Mário de Andrade:ramais e caminho. São Paulo, Duas Cidades, 1972.

MOTTA, Leonardo - Sertão alegre. Rio de Janeiro, Ouro, 1968.

- Cantadores. (poesia e linguagem do sertão cearense). Rio de Janeiro, Castilho, 1921 